\title{
Transacting Transcriptional Activation of Human Spumaretrovirus LTR in Infected Cells
}

\author{
Axel Rethwilm, ${ }^{1}$ Kazuyasu Mori, Bernd Maurer, and Volker ter Meulen \\ Institut für Virologie, Universität Würzburg, Versbacher Strasse 7, 8700 Würzburg, Federal Republic of Germany
}

Received August 25, 1989; accepted December 11, 1989

\begin{abstract}
The long terminal repeat (LTR) of the human spumaretrovirus (HSRV) was examined with respect to its ability to function as transcriptional promotor in virus-infected and uninfected cells. Transient transfections using a plasmid in which the $3^{\prime}$ LTR of HSRV was coupled to the bacterial chloramphenicol acetyltransferase (cat) gene revealed that the level of HSRV LTR-directed cat gene expression was markedly increased in HSRV-infected cells compared to uninfected cells. Northern blot analysis of cat mRNA from transfected cultures suggests that transactivation of HSRVdirected gene expression occurs at the transcriptional level. (1) 1990 Academic Press, Inc.
\end{abstract}

Spumaretroviruses, which are also called foamy viruses, are a distinct group of retroviruses (1), ubiquitous in nonhuman primates, bovines, and felines (2). They induce persistent infections in their hosts without apparent clinical disease (2). Isolation of human foamy viruses have been reported from primary cultures of tissues of various human diseases (3-6) and a low seroposivity has been found in populations of East Africa and pacific islands $(7,8)$. However, so far any defined disease has not been associated with this group of viruses (9).

The recent reports on the molecular biological characterization of a human isolate obtained in 1971 from nasopharyngeal carcinoma cells (6) has again raised interest in this agent since its genomic organization shows similarities to the other human retroviruses (1, 9). It has been found that the HSRV genome carries the information for at least four gene products in addition to the gag, pol, and env genes characteristic for all retroviruses. Three of these, called bel 1,2, and 3 are located between the env gene and the $3^{\prime}$ LTR. The fourth additional open reading frame (ORF), $\mathrm{S} 1$, is located between the $p o l$ and the env gene $(10,11)$. Since there is a limited but significant homology between the bel 1 ORF of HSRV and the human immunodeficiency virus (HIV) type 2 tat gene, a similar function of these genes has been suggested (12). To assess this hypothesis we investigated the activity of LTR-directed transcription in virus-infected and uninfected cells.

Parent plasmid for the LTR cat constructs was the cat expression plasmid pSV2cat (13). Deletion of a 501-base pair (bp) Accl/Hindlll fragment containing the SV40 regulatory sequences and insertion of Hindlll or $\mathrm{Bg} / \mathrm{ll}$ linkers led to plasmids pOcat- $\mathrm{H}$ and $\mathrm{pOcat}-\mathrm{Bg}$, re-

\footnotetext{
1 To whom requests for reprints should be addressed.
}

spectively. The construct pHSRVcat was derived from the viral DNA clone pHSRV-B52, which harbors the sequences from nucleotide position 9103 in the bel 1 ORF to the $3^{\prime}$ end of the viral genome (10). Plasmid pHSRV-B52 was cut with Saul at nucleotide position +316 (start of transcription is +1 ) in the U5 region of the $3^{\prime} L T R$, as deduced from cap site mapping (11), and $B g / l l$ linkers were inserted leading to $\mathrm{pHSRV}-\mathrm{B} 52-\mathrm{Bg}$. A 1488-bp Bg/ll fragment of pHSRV-B52-Bg, running from a Bglll site at nucleotide position 9788 in the bel 2 ORF to the newly created Bg/ll site, was cloned in sense orientation $5^{\prime}$ to the cat gene of pOcat-Bg. Thus, pHSRV cat contains 262 bp of flanking viral sequences prior to the start of the LTR (Fig. 1). For comparative purposes control plasmids pSV2cat, known to function in a wide variety of cell types (13), and pCMVcat were included in transfection experiments. Plasmid PCMVcat was constructed by inserting a 815-bp Hindllilinked Ball/Sphl fragment from pRR23 containing the human cytomegalovirus immediate early gene enhancer/promotor (14) into pOcat-H. As shown in Fig. 1 $\mathrm{pCMV}$ cat harbors hCMV sequences from nucleotide positions -670 to +145 .

HSRV was grown on baby hamster kidney cells (BHK-21) and on human glioblastoma cell line U-251 $M G$ as described (15). Twenty micrograms of DNA was transfected into $5 \times 10^{5}$ cells in a petri dish $(80 \mathrm{~mm})$ as a calcium phosphate coprecipitate (16). For transfection of HSRV-infected cells $2 \mathrm{ml}$ cell-free supernatant from a HSRV-infected culture was added to the freshly seeded cells 1 day prior to transfection. After adding the DNA precipitate cells were incubated overnight at $37^{\circ}$ followed by a glycerol shock and change of medium (17). Cells were harvested $48 \mathrm{hr}$ after transfection and processed as described (13). CAT assays were performed with $50 \mu \mathrm{g}$ of protein as determined using a commercial protein assay (Bio-Rad), $0.1 \mu \mathrm{Ci}\left[{ }^{14} \mathrm{C}\right]$ chlor- 

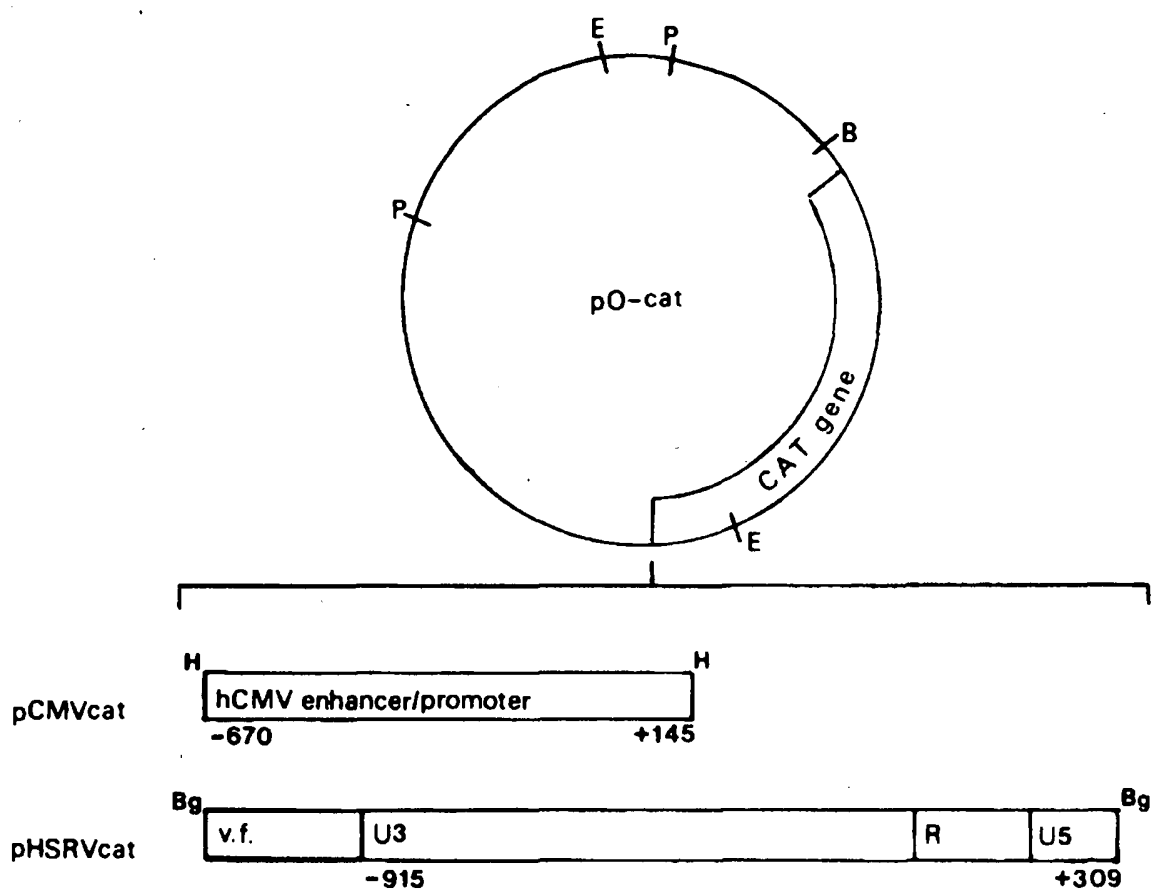

FIG. 1. Plasmids used for transfections. Construct pHSRVcat harbors a 1488-bp Bg/ll fragment $5^{\prime}$ to the cat gene of pOcat-Bg. comprising 262 bp of flanking viral sequences (V.f.), U3, R, and U5 regions to nucleotide position +309 of the $3^{\prime}$ LTR. Plasmid pCMVcat harbors the immediate early gene enhancer/promotor region of $\mathrm{hCMV}^{\prime}$ to the cat gene of pOcat-H. Molecular cloning was performed according to established methods (28), and plasmid constructions were confirmed by extensive restriction enzyme digestions. Enzymes were used as specified by the manufacturer (BRL and Boehringer-Mannheim). BamHI (B), BgIII (Bg), EcoRI (E). HindIII (H), Pstl (P).
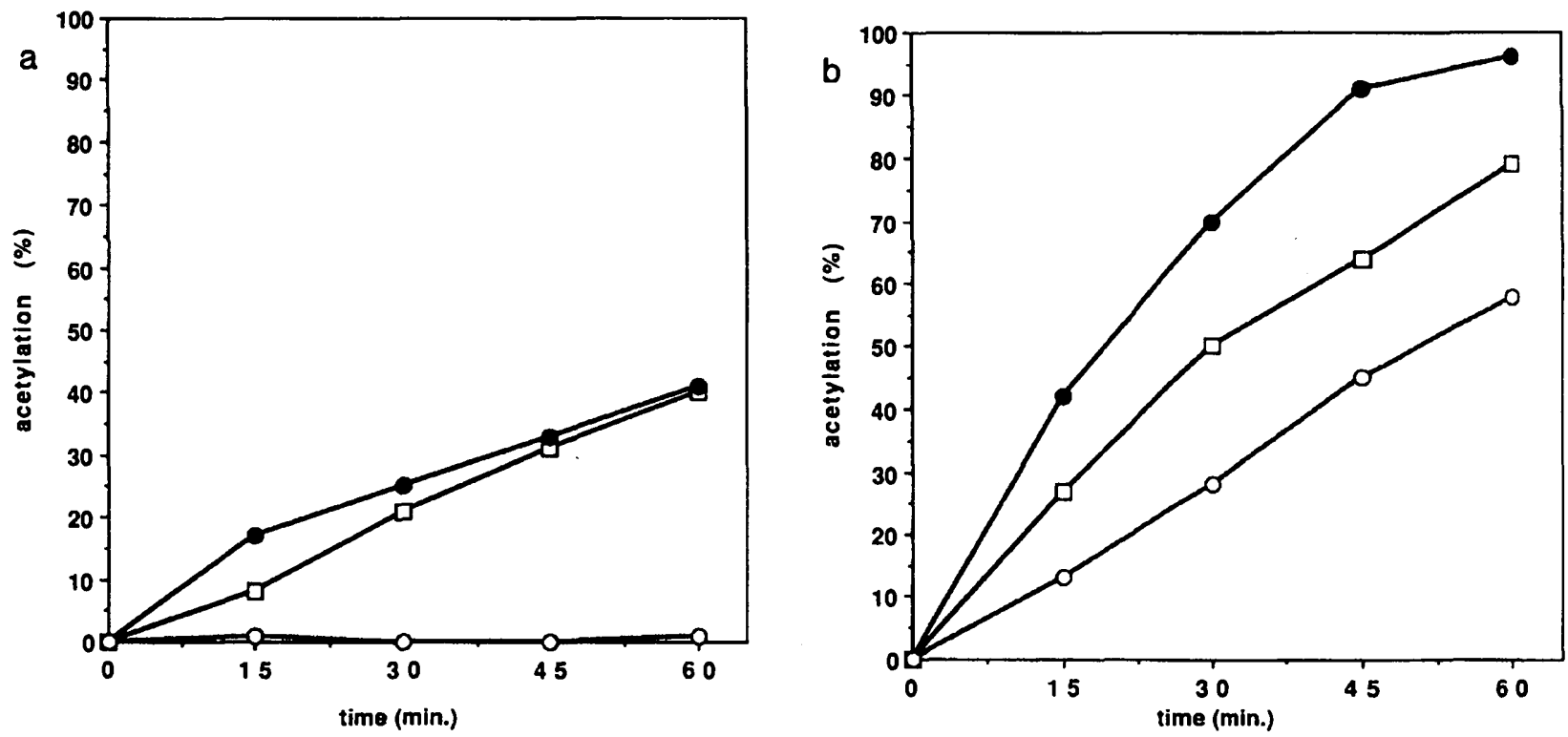

FIG. 2. Time course of the CAT activity in extracts prepared from BHK-21 cells (a) and HSRV-infected BHK-21 cells (b). Cultures were transfected with pHSRVcat (O), pCMVcat ( $\bullet$, and pSV2cat ( $\square$ ). The mean of three experiments is shown. 
TABLE 1

COMPILATION OF CAT ASSAYS USING LYSATES FROM HSRV-INFECTED AND UNINFECTED BHK-21 AND U-251 MG CELLS

\begin{tabular}{|c|c|c|c|}
\hline pSV2cat & pCMVcat & pHSRVca & \\
\hline \multicolumn{4}{|c|}{ BHK-21 } \\
\hline 39.7 & 40.9 & 0.7 & $\%$ conversion \\
\hline 1.0 & 1.03 & 0.02 & relative to pSV2cat \\
\hline \multicolumn{4}{|c|}{ BHK-21 HSRV infected } \\
\hline 79.3 & 95.6 & 57.7 & $\%$ conversion \\
\hline 1.0 & 1.2 & 0.73 & relative to pSV2cat \\
\hline \multicolumn{4}{|c|}{$\mathrm{U}-251 \mathrm{MG}$} \\
\hline n.d. & n.d. & 0.4 & $\%$ conversion \\
\hline \multicolumn{4}{|c|}{ U-251 MG HSRV infected } \\
\hline n.d. & n.d. & 17.0 & $\%$ conversion \\
\hline
\end{tabular}

Note. The percentage of acetylated chloramphenicol from total input chloramphenicol and the percentage of acetylation relative to that obtained with control plasmid pSV2cat are shown. Ten micrograms of protein were run in a 1 -hr reaction, and the mean value from three experiments was determined. n.d., not done.

amphenicol (Amersham), and $3 \mu M$ acetyl-CoA (Sigma)

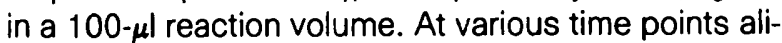
quots of $20 \mu$ l were taken and extracted with ethyl acetate. Acetylated and unacetylated chloramphenicol were separated by ascending thin layer chromatography, and chromatography plates were exposed to Xray films overnight. Acetylated chloramphenicol was calculated from total input chloramphenicol by cutting out the spots from the chromatography plate and liquid scintillation counting. All values were determined from three independent transfections and CAT assays.

As shown in Fig. $2 a$ the HSRV LTR-driven cat gene is nonfunctional when transfected into uninfected BHK-21 cells. CAT activities in lysates prepared from pSV2cat and pCMVcat transfected cells increase linearly with incubation time, indicating efficient uptake and expression of DNA. In contrast, a high level of CAT activity was found upon transfection of pHSRVcat into HSRV-infected BHK-21 cells (Fig. 2b), indicating that like HIV and HTLV $(18,19)$ HSRV encodes for a transactivator capable of enhancing transcription from its own LTR. Levels of CAT activities using the control plasmids were found to be about twofold higher in infected cells compared to uninfected cells (Fig. 2b, Table 1). It has been reported recently that retroviral transactivators may stimulate heterologous viral promotors, such as the SV 40 promotor $(20,21)$. Whether this mechanism accounts for the observed effect remains to be elucidated. On the other hand, uninfected and infected cells may differ in the uptake of foreign DNA by the transfection procedure used. We therefore expressed CAT levels relative to those of $p S V 2 c a t$ as summarized in Table 1. By this calculation gene expression directed by the HSRV LTR was enhanced by a factor of 36.5 in HSRV-infected BHK-21 cells as compared to uninfected cells. Stimulation was found to be in the same range using the U-251 MG cell line.

Different mechanisms of transactivator-mediated stimulation of retroviral transcription have been suggested especially for HIV (22-24). Since several reports indicated a regulation at least in part at the post-tran-

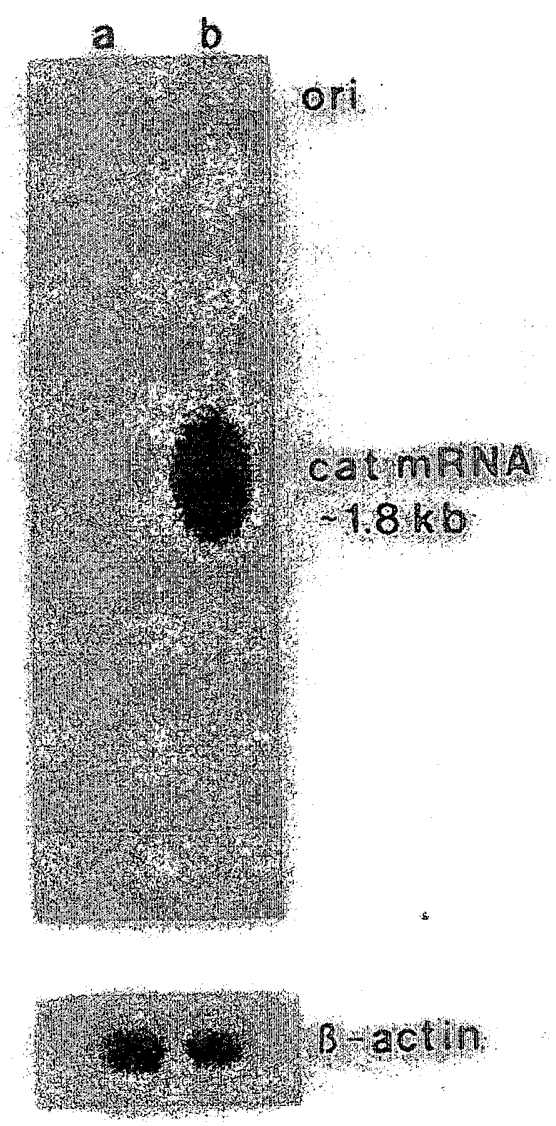

Fig. 3. Northern blot hybridization of cat mRNA from pHSRVcattransfected cultures. Two micrograms of poly $(A)^{+}$RNA from BHK-21 (a) and $1 \mu \mathrm{g}$ from HSRV-infected BHK-21 cells (b) were separated on a denaturating agarose gel and blotted onto a nylon membrane. The filter was hybridized overnight with a cat-specific probe in $50 \%$ formamide, $100 \mu \mathrm{g} / \mathrm{ml}$ t-RNA, $5 \times$ SSC, $0.02 \mathrm{M}$ sodium pyrophosphate, $5 \times$ Denhardt's solution, and $1 \%$ SDS at $42^{\circ}$, washed three times for $30 \mathrm{~min}$ in $2 \times$ SSC, $0.1 \%$ SDS at $68^{\circ}$, and exposed to Cronex X-ray film (DuPont). The probe was washed off the filter as specified by the manufacturer, and the filter was rehybridized with a $\beta$-actin probe under the same conditions. Probes were labeled according to Feinberg and Vogelstein (33) to a specific activity of $5 \times 10^{8} \mathrm{cpm} / \mu \mathrm{g}$. 
scriptional level $(25,26)$, we investigated whether HSRV LTR-directed cat mRNA could be detected in uninfected and HSRV-infected cells. Petri dishes with uninfected and HSRV-infected BHK-21 celis (a number of six each) were transfected with pHSRVcat. Forty-eight hours later cells from one petri dish were used to prepare cellular extracts for CAT assay and RNA from the cultures transfected in parallel was extracted by the guanidinium-isothyocyanate method (27). Poly $(A)^{+}$ RNA was selected on oligo(dT) cellulose (28), separated on a formaldehyde-containing agarose gel and blotted onto GeneScreen plus membranes (DuPont). Filters were hybridized with an internal 250-bp EcoRI/ Hind III fragment from the cat gene and were rehybridized with a $\beta$-actin probe (29). As shown in Fig. 3 no cat mRNA could be detected in uninfected BHK-21 cells transfected with pHSRVcat (lane a), while in HSRV-infected cells cat mRNA approximately $1.8 \mathrm{~kb}$ in size was clearly detected with a cat-specific probe (lane b). CAT assays from cultures transfected in parallel showed $0.4 \%$ conversion of chloramphenicol in uninfected and $64.6 \%$ conversion of chloramphenicol in HSRV-infected cells, respectively. Thus, levels of cat mRNA in Northern blot and levels of CAT protein in CAT assay correlate well in this experiment. This result suggests that transactivation of HSRV LTR-directed gene expression occurs mainly at the transcriptional level. However, further experiments are needed to elucidate the mechanism by which HSRV transactivates its own LTR more precisely. As a first step to identify the HSRV gene responsible for transactivation we have constructed an infectious molecular clone for HSRV (A. Rethwilm et al., manuscript in preparation). Deletion mutants of this clone as well as of the HSRV LTR in the HSRVcat plasmid should allow the investigation of the specific transactivation mechanism of HSRV.

The pathogenic human retroviruses of the lentiviral and oncoviral group both encode for transactivators. Evidence has been presented that the viral proteins responsible for transactivation may alter the expression of cellular genes and as in the case of HTLVI TAX protein may be directly involved in viral pathogenicity (3032). The presence of a transactivator in HSRV-infected cells should therefore reinforce studies on the molecular biology and epidemiology of HSRV. This view is strengthened if one takes into account that the overall genome structure of HSRV closely resembles those of HIV and HTLV (1).

\section{ACKNOWLEDGMENTS}

We thank D. Neumann-Haefelin (Freiburg, FRG) for the BHK-21 cell line, D. D. Bigner (Durham, NC) for the U-251 MG cell line, R. M Flügel (Heidelberg, FRG) for HSRV wild type, and $B$. Fleckenstein (Erlangen, FRG) for pRR23. We are indebted to I. Horak for helpful discussion and critical reading of the manuscript, $C$. Römmelt for expert technical assistance, and $\mathrm{H}$. Kriesinger for typing the manuscript. This work was supported by a grant from the Bundesministerium für Forschung und Technologie

\section{REFERENCES}

1. Maurer, B., and Flügel, R. M., AlDS Res. Hum. Retroviruses 4, 467-473 (1988).

2. HoOKS, J. J., and DETRICK-HOOKS, B., In "Comparative Diagnosis of Viral Diseases" (E. Kurstak and C. Kurstak, Eds.), Vol. IV, pp. 599-618. Academic Press, New York, 1981.

3. WeRner, J., and GelderblOM, H., Lancet 1, 258-259 (1979).

4. Young, D., et al., Arch. Gesamte Virusforsch. 42, 228-234 (1973).

5. CAMERON, K. P. et al. Lancet 2, 796 (1978).

6. ACHONG, B. G., et al., J. Natl. Cancer Inst. 46, 299-307 (1971).

7. Muller, H. K. et al., J. Gen. Virol. 47, 399-406 (1980).

8. LOH, P. C., et al., Intervirology 13,87-90 (1980).

9. WeISS, R. A., Nature (London) 333, 497-498 (1988).

10. FLÜGEL, R. M., et al., EMBO J. 6, 2077-2084 (1987).

11. Maurer, B., et al., J. Virol. 62, 1590-1597 (1988).

12. MAURER, B., and FLÜGEL, R. M., FEBS Lett. 222, 286-288 (1987).

13. Gorman, C. M., et al., Mol. Cell. Biol. 2, 1044-1051 (1982).

14. Boshardt, M., et al., Cell 41, 521-530 (1985).

15. Neumann-Haefelin, D., et al., Med. Microbiol. Immunol. 172, 75-86 (1983).

16. Graham, F., and van der EB, A., Virology 52, 456-457 (1973).

17. PARKER, B., and StARK, G., J. Virol. 31, 360-369 (1979).

18. Sodroski, J. G., et al., Science 225, 381-385 (1984).

19. Sodroski, J. G., et al., Science 227, 171-173 (1985).

20. SAITO, S. et al., J. Virol. 62, 644-648 (1988).

21. Williams, J. L., et al., Nucleic Acid Res. 17, 5737-5749 (1989).

22. Muesing, M. A., et al., Cell 48, 691-701 (1987).

23. KAO, S.-Y., et al., Nature (London) 330, 489-493 (1987).

24. Braddock, M. et al., Cell 58, 269-279 (1989).

25. Rosen, C. A., et al., Nature (London) 319, 555-559 (1986).

26. Cullen, B. R., Cell 46, 973-982 (1986).

27. CHIRGWIN, J. M., et al., Biochemistry 18, 5294-5299 (1979).

28. Maniatis, T., et al., "Molecular Cloning: A Laboratory Manual." Cold Spring Harbor Laboratory, Cold Spring Harbor, NY. 1982.

29. Gunning, P., et al., Mol. Cell. Biol. 3, 787-795 (1983).

30. GReEne, W. C., et al., Science 232, 877-880 (1986).

31. KOKA, P., et al., J. Virol. 62, 4353-4357 (1988).

32. NagAtA, K., et al., J. Virol. 63, 3220--3226 (1989).

33. Feinberg, A. P., and Vogelstein, B., Anal. Biochem. 137, 266$267(1984)$ 